Geopolítica(s) Revista de estudios sobre espacio y poder ISSN: 2172-3958

https://dx.doi.org/10.5209/geop.69137

\title{
Geopolítica de la pandemia de COVID-19
}

\author{
Equipo de Dirección ${ }^{1}$
}

Cómo citar: Dirección. (2020). Geopolítica de la pandemia de COVID-19. Geopolítica(s). Revista de estudios sobre espacio y poder, 11(Especial), 11-13.

Los que hemos vivido esta pandemia causada por el virus bautizado como SARSCoV-2 - causante de la enfermedad que la comunidad científica ha acordado denominar COVID-19 por razones geopolíticas entre otras, ya que de este modo no se alude a ningún lugar o grupo humano particular ${ }^{2}-\mathrm{y}$ sus efectos creo que nunca la olvidaremos. Es uno de esos hechos biológicos, pero también sociales, económicos y políticos que va a marcar diferencias: un "hecho social total", como señala Ramonet (2020). Pero los que de una u otra manera nos dedicamos, de una u otra forma, a la geopolítica $-\mathrm{O}$ al estudio de las relaciones entre espacio y poder en un sentido más amplio - lo recordaremos también por la explosión de explicaciones "geopolíticas" de la pandemia. Efectivamente, no hay día que en los periódicos o en los medios académicos no aparezca un artículo, foro o videoconferencia sobre la COVID-19 que no lleve la palabra "geopolítica" en su título. Han surgido tantos expertos en geopolítica como epidemiólogos aficionados. En España dicen sarcásticamente que todas las personas somos entrenadores de fútbol frustrados, y que cuando vemos un partido u opinamos sobre él lo hacemos siempre como si fuéramos entrenadores profesionales. Nos tememos que está pasando algo similar.

Pero bienvenidos sean los nuevos especialistas, porque, en cualquiera de los casos, buena parte de lo que está ocurriendo son temas de los que también se ocupa la geopolítica en sus diferentes escalas: la distinción general entre interior y exterior, los cierres de fronteras, las ciudades vacías, los confinamientos personales... todos estos y muchos más son temas geopolíticos. Por lo tanto, se tienen que analizar desde la geopolítica, y los que llevamos años intentando hacer indagaciones y estudios de carácter geopolítico tenemos algo que decir también. Es una de las dimen-

1 Este editorial, por su carácter urgente, no ha podido ser elaborado por el Consejo de Redacción, y ha sido escrito por el director y la subdirectora de la revista.

2 El acuerdo es explicado así por el Director General de la OMS: "Según las pautas acordadas entre la Organización Mundial de la Salud, la Organización Mundial de Sanidad Animal y la Organización de las Naciones Unidas para la Agricultura y la Alimentación, tuvimos que encontrar un nombre que no se refiriera a una ubicación geográfica, un animal, un individuo o un grupo de personas, y que también fuera pronunciable y estuviera relacionado con la enfermedad" (WHO, 2020). 
siones del estudio de las enfermedades a nivel poblacional, junto con las sociales, económicas y políticas, entre otras.

Por eso, al poco de comenzar el confinamiento, quizás guiados por la impotencia que se siente al estar así, desde la dirección de la revista nos pusimos en contacto con los compañeros y compañeras de los consejos editores de Geopolítica(s), así como otros amigos de la revista (en particular los miembros de la Red de Estudios Socioespaciales), para proponerles hacer un número especial sobre la geopolítica de la pandemia de COVID-19. En seguida tuvimos una respuesta positiva, y nos pusimos manos a la obra.

Las reflexiones que hemos hecho se han tenido que hacer, en términos generales, sobre bases nuevas, porque es sorprendente la ausencia de estudios previos sobre geopolítica y pandemias. Consultada una de las base de datos más importantes, la Web of Science, apenas cuatro trabajos aluden a esta relación (geopolitics y pandemics). Uno de ellos es sobre la promoción de políticas públicas de salud (Labonte, 2011), otro sobre la experiencia histórica de los judíos italianos, marcada entre otras cosas por una epidemia en los años 1980 (Nissan, 2011), uno más sobre el impacto de la epidemia de VIH en la antigua Unión Soviética (Ambrosio, 2006), y sólo uno de una experiencia algo equiparable a la actual, la gripe aviar (Aaltola, 2012), aunque con mucho menos impacto.

Quizás uno de los pocos textos que pueda ser de utilidad para analizar la relación entre pandemia y geopolítica sea el de Summers (2012) sobre la geopolítica de la gran peste de Manchuria en 1910-11. El libro se ocupa de estudiar la forma en que se extendió una epidemia de peste neumónica en esa región entonces en disputa entre Japón, China e incluso Rusia, debido a la interacción entre el ser humano y otras especies animales, en concreto la marmota siberiana que era cazada para alimentarse por los pastores manchúes. En este sentido, tiene muchas reflexiones valiosas sobre la relación entre naturaleza y humanidad que afectan claramente a una geopolítica del medio ambiente. Las partes que específicamente se ocupan de la geopolítica de las pandemias tienen que ver, en primer lugar, con las diferentes aproximaciones al control de la peste por parte de las autoridades coloniales japonesas en Manchuria meridional, las autoridades rusas de facto en el norte y el gobierno chino, cuya pugna dificultó la supresión de la plaga; y, por otra parte, con la forma en que se produjo la cooperación internacional para suprimir la enfermedad, que se materializó en una International Plague Conference que tuvo lugar en Mukden, en abril de 1911.

Analizando esos hechos desde el siglo XXI, el autor es quizás demasiado optimista respecto a una respuesta mucho más organizada a una pandemia en la actualidad. Considera que no sólo los avances científicos de la medicina en el control de estas epidemias y pandemias han sido espectaculares a lo largo del siglo pasado, sino que también las organizaciones internacionales del ámbito de la salud humana se han consolidado y no están en el nivel embrionario de aquella época. Pero la medicina no es omnipotente, y las organizaciones internacionales sufren los embates de los gobiernos, como muestra la suspensión a la financiación de la Organización Mundial de la Salud (OMS) que el gobierno de Estados Unidos ha dictado el 14 de abril pasado en plena escalada de la pandemia en ese país: "Hoy ordeno a mi Gobierno suspender los fondos a la OMS mientras reviso su conducta para determinar el rol de la OMS y su grave mal manejo y encubrimiento de la expansión del 
coronavirus", anunció Trump durante una rueda de prensa en la Casa Blanca (EFE / eldiario.es, 2020).

Los antedichos son algunos de los temas de los que, en general, se van a ocupar los textos reunidos aquí, que están escritos desde diversas perspectivas teóricas (más tradicionales y más críticas) y metodológicas (del positivismo al postestructuralismo), como es política de la revista. La mayor parte de ellos son estudios de casos, pero que ilustran pautas generales, y, sobre todo, añaden argumentos que, obviamente, están pendientes de un sosegado análisis final cuando termine esto. Se trata de textos cortos, que tienen por objetivo ofrecer argumentos a la comunidad científica y al público en general sobre la pandemia de COVID-19 desde una perspectiva de estudio de las relaciones entre espacio y poder. El carácter urgente de su escritura está motivado por ese carácter, y es muy posible que den lugar a textos más meditados que tendrán mayor elaboración. Del mismo modo, la evaluación de los mismos se ha limitado a la evaluación interna en el Consejo de Redacción.

El orden de los artículos en este número se corresponde, en términos generales, con la recepción de los mismos, como suele ser habitual en la revista. Esta disposición permite observar - aunque no hay una regla general - cómo han ido evolucionando las preocupaciones de los autores: si al principio se centraban más en las políticas de los Estados y otros organismos, en los últimos textos sobresalen las digresiones sobre los escenarios postpandemia..

\section{Referencias}

Aaltola, M. (2012). Avian Flu and Embodied Global Imagery: A Study of Pandemic Geopolitics in the Media. Globalizations, 9(5), 667-680.

Ambrosio, T. (2006). The geopolitics of demographic decay: HIV/AIDS and Russia's greatpower status. Post-Soviet Affairs, 22(1), 1-23.

EFE / eldiario.es. (2020). Trump suspende los fondos de EEUU a la OMS en plena pandemia y la acusa de ocultar la expansión del coronavirus. eldiario.es, 15 de abril. Recuperado de https://www.eldiario.es/internacional/Trump-suspende-EEUU-OMS-COVID19_0_1016998330.html

Labonte, R. (2011). Toward a post-Charter health promotion. Health Promotion International, 26(Supl. 2), II183-II186.

Nissan, Ephraim (2011). Aspects of Italy's Jewish experience, as shaped by local and global factors. European Review of History - Revue Europeenne d'Histoire, 18(1), 131-142.

Ramonet, I. (2020). La pandemia y el sistema-mundo. La Jornada, 25 de abril. Recuperado de https://www.jornada.com.mx/ultimas/mundo/2020/04/25/ante-lo-desconocido-lapandemia-y-el-sistema-mundo-7878.html

Summers, W. C. (2012). The Great Manchurian Plague of 1910-1911. The Geopolitics of an Epidemic Disease. New Haven, CT: Yale University Press.

WHO. (2020). WHO Director-General's remarks at the media briefing on 2019-nCoV on 11 February 2020. WHO, 11 de febrero. Recuperado de https://www.who.int/dg/speeches/detail/who-director-general-s-remarks-at-the-mediabriefing-on-2019-ncov-on-11-february-2020 